\title{
Early heat waves over Italy and their impacts on durum wheat yields
}

\author{
G. Fontana, A. Toreti, A. Ceglar, and G. De Sanctis \\ European Commission, Joint Research Centre, Ispra (VA), Italy \\ Correspondence to: G. Fontana (giovanna.fontana@jrc.ec.europa.eu)
}

Received: 12 February 2015 - Published in Nat. Hazards Earth Syst. Sci. Discuss.: 4 May 2015

Accepted: 13 July 2015 - Published: 28 July 2015

\begin{abstract}
In the last decades the Euro-Mediterranean region has experienced an increase in extreme temperature events such as heat waves. These extreme weather conditions can strongly affect arable crop growth and final yields. Here, early heat waves over Italy from 1995 to 2013 are identified and characterised and their impact on durum wheat yields is investigated. As expected, results confirm the impact of the 2003 heat wave and highlight a high percentage of concurrence of early heat waves and significant negative yield anomalies in 13 out of 39 durum wheat production areas. In south-eastern Italy (the most important area for durum wheat production), the percentage of concurrent events exceeds $80 \%$.
\end{abstract}

\section{Introduction}

According to the IPCC Fifth Assessment Report, the warming of the climate system is unequivocal and has been particularly pronounced since the 1970s (Hartmann et al., 2013). In the Euro-Mediterranean region, significant changes in temperature extremes (e.g. increase in warm days and nights, warm spells and heat waves) have also been reported (Hartmann et al., 2013; Kuglitsch et al., 2010; Toreti and Desiato, 2008; Della-Marta et al., 2007). In 2003, Europe experienced an exceptionally warm and dry summer (Black et al., 2004), with summer temperature anomalies, with respect to the $1961-1990$ mean, greater than $3{ }^{\circ} \mathrm{C}$ in a very large area (Schär et al., 2004). That extreme summer began with a heat wave in June, continued through July and was characterised by another heat wave in early August (Black et al., 2004). In general, extreme weather conditions can strongly affect arable crop growth and their yields; thus, compelling reasons for analysing extreme temperature events and their relation with agricultural yields are evident. Plant growth and repro- duction are less efficient at temperatures above the optimal range. The main critical responses under warmer conditions are faster crop development leading to shorter growing periods and lower yields, limited crop growth and acceleration of senescence, greater water evaporation from soil and transpiration from crops (Eyshi Rezaei et al., 2015).

Many important grain crops tend to have lower yields when maximum temperature increases, primarily because heat accelerates the plant developmental cycle and reduces the duration of the grain-filling period (Rosenzweig and Hillel, 1998). Exposure to extremely high temperatures (e.g. greater than $35^{\circ} \mathrm{C}$ ) induces a wide variety of perturbations in cellular structures and metabolic processes (Nakamoto and Hiyama, 1999). Even isolated occurrences of extreme high temperatures around a sensitive stage of crop development, such as flowering and grain-filling, can reduce grain yield considerably, while a continuous period of extreme high temperatures can result in almost total yield loss (Semenov and Shewry, 2011). Recent evidence suggests that even short exposures to high temperatures can be crucial for the final yield (Schlenker and Roberts, 2009; Wassmann et al., 2009). Heat stress often occurs simultaneously with drought stress, but both can have very different effects on various physiological, growth, developmental and yield forming processes (Boote et al., 2005). The effects of drought and heat stress on the crop depend on the occurrence of the event in relation to the crop phenological stage; however, they are among the most important environmental factors influencing crop growth and yield (Gobin, 2012).

Wheat can be affected by heat stress at different phenological stages, but this stress is more harmful during the reproductive phase than during the vegetative phase due to the direct effect on grain number and dry weight (Wollenweber et al., 2003). The number of produced grain is a function of the number of spikelets and the number of kernels per 
spikelet. Spikelets might be initiated at temperatures higher than $1.5^{\circ} \mathrm{C}$ (Slafer and Rawson, 1995). However, optimum temperatures for this phase are between 9.3 and $11.9^{\circ} \mathrm{C}$, with temperatures greater than $25^{\circ} \mathrm{C}$ being sub-optimal. High temperatures during early spike development reduce the number of spikelets per head and/or the number of seeds per spikelet (Johnson and Kanemasu, 1983). Temperatures above $31{ }^{\circ} \mathrm{C}$ immediately before anthesis of wheat (triticum aestivum) reduce grain yield by inducing pollen sterility, thus reducing grain numbers (Wheeler et al., 1996a, b). However, as reported by Porter and Gawith (1999), at $50 \%$ of anthesis also temperatures around $27^{\circ} \mathrm{C}$ induce sterility. Furthermore, different experiments on wheat have shown that duration and rate of grain growth are reduced by heat stress (Dias and Lidon, 2009; Viswanathan and Khanna-Chopra, 2001). Stone and Nicolas (1995) examined the effects of timing of heat stress during grain filling on wheat grain growth and found that mature individual kernel mass is most sensitive to heat stress in early grain filling and becomes progressively less sensitive throughout grain filling.

Wheat is one of the main products of Italian agriculture and Italy is the most important producer of durum wheat in Europe. In 2013, the Italian durum wheat (Triticum turgidum L. var. durum) production was 4.2 million tonnes. In Italy, durum wheat represents approximately $55 \%$ of the total wheat production (http://www.ec.europa.eu/eurostat/ data), while in the European Union, as a whole, it only reaches $5 \%$. For these reasons in Italy, the weather effects on winter durum wheat are of primary interest (Dalla Marta et al., 2011). Winter durum wheat is cultivated in southern/central Italy and in some areas of northern Italy, with about 1.2 million hectares dedicated to this crop. Usually, it is sown in October-November and harvested at the beginning of July of the following year. The shooting phase starts in April, when the average temperature is around $10-12^{\circ} \mathrm{C}$, while ripening starts when the average temperature reaches about $18-20{ }^{\circ} \mathrm{C}$.

In this study, we analyse early heat waves that occurred in Italy from 1995 to 2013 and annual yield of durum wheat at province level. In particular, we focus on the most important (in term of acreages) 39 Italian provinces for the cultivation of durum wheat. As for the early heat waves, we focus on the most sensitive period for winter wheat, i.e. from May to June. The main objective of this study is to assess the impact of early heat waves on the final yield of durum wheat in the main productive Italian provinces.

\section{Data and methods}

\subsection{Crop yields}

Durum wheat yield and acreage annual time series from 1995 to 2013 have been retrieved from the Italian National Institute of Statistics (ISTAT). Out of all provinces, only 39 with substantial durum wheat production are selected here. These provinces have a relative durum wheat acreage higher than $0.5 \%$ of the total national acreage (in $80 \%$ of the years). In addition, also the provinces with a relative durum wheat acreage higher than $0.5 \%$ of the total national acreage during the last 5 years are included. The continuous innovation of agricultural technology and introduction of new cultivars, combined with dynamical changes in fertilisation, can result in a trend component affecting the durum wheat yield time series. Thus, in order to identify and take into account potential trend, the raw yield time series are analysed by applying a non-parametric procedure. The Mann-Kendall test (Kendall, 1975; Mann, 1945) is run for each time series and when the null hypothesis of stationarity is rejected a trend is estimated by using the Theil-Sen method (Sen, 1968). Then, the identified trend is removed from the time series and the values expressed as anomalies with respect to the 1995-2013 mean. Finally, significant negative yield anomalies are defined as events with a value of yield anomaly lower than the estimated 30th percentile.

\subsection{Heat waves}

The JRC-MARS meteorological database (Van der Goot et al., 2004) is used in this study to analyse early heat waves. It includes daily data from almost 4000 weather stations, covering the period 1975-2013, interpolated on a regular $25 \mathrm{~km} \times 25 \mathrm{~km}$ grid. The raw station data as well as the daily values undergo a quality check procedure before entering in the interpolation process. Here, daily maximum temperature time series, covering the period 1995-2013, have been extracted from selected grid cells over the 39 selected Italian provinces. Early heat waves (i.e. occurring in the period May-June) are identified and characterised by using an approach derived by the one proposed by Kuglitsch et al. (2010). A heat wave is defined as a period of three or more consecutive hot days (an interruption of 1 day is allowed), where hot days are defined as days having daily maximum temperature above the 90th percentile. This threshold is calculated for each day by using the full time period (19952013) and samples of 15 days centred on the day under analysis. Then for the period May-June, heat waves are characterised by using three indicators: intensity, number of events and total length.

The intensity is calculated as follows:

$$
\sum_{i} \max \left(T X_{i}-T X_{i}^{90}, 0\right),
$$

where $T X_{i}$ represents the daily maximum temperature at day $i$ and $T X_{i}^{90}$ is the 90th percentile threshold of that day. In terms of impacts on durum wheat, the use of the 90th percentile can be justified by considering that uncertainties (of the order of some degrees Celsius) characterise temperature thresholds at which heat stress has a significant impact; specific experiments have shown that wheat becomes progres- 


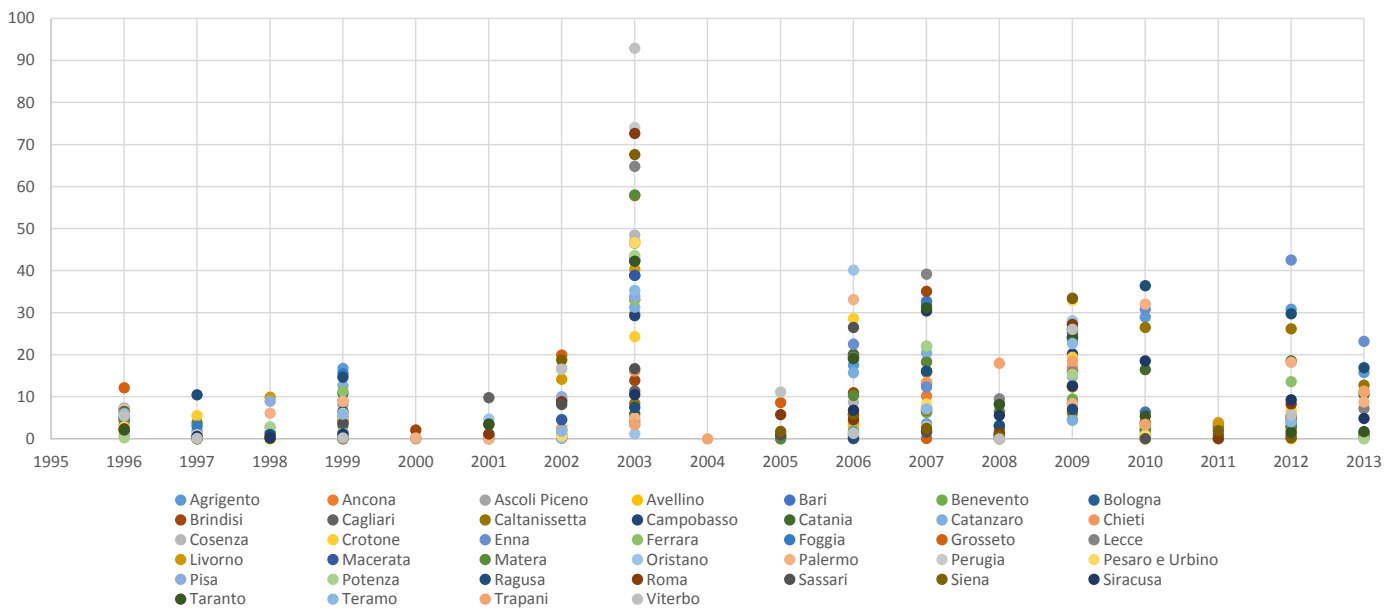

Figure 1. Estimated intensity of the early heat waves affecting the selected 39 Italian provinces in the period 1995-2013. Values are in degrees and colours are associated with the provinces.

sively less sensitive throughout grain filling (Stone and Nicolas, 1995); the median of the estimated thresholds ranges from $24^{\circ} \mathrm{C}$ (first of May) to $32{ }^{\circ} \mathrm{C}$ (end of June) with a 10 day increase of $1.4^{\circ} \mathrm{C}$; for non-irrigated fields the canopy temperature is higher than the $2 \mathrm{~m}$ air temperature (measured by the available meteorological stations) and differences up to $7^{\circ} \mathrm{C}$ have been reported by Siebert et al. (2014).

In addition, the climatic water balance is also analysed in some specific cases. It is calculated as the difference between precipitation and potential evapotranspiration at the daily scale. Potential evapotranspiration is estimated by using the Penman-Monteith equation (Allen et al., 1998). The climatic water balance is used to gain a better understanding of cases with negative yield anomalies but no early heat wave occurrence.

\section{Results}

The intensity of the identified early heat waves during the period May-June (1995-2013) and the number of provinces affected by heat waves for each year are shown in Figs. 1 and 2. The 2003 peak is evident in both indicators. All provinces considered for this study experienced the 2003 heat wave, with an intensity that exceeded $70^{\circ} \mathrm{C}$ in the provinces of Perugia and Rome (central Italy), and reached about $93^{\circ} \mathrm{C}$ in Viterbo (central-western Italy). Significant early heat waves can also be observed for instance in 2006, 2007 and 2009. In particular, during 2009 all provinces experienced heat waves, but the average intensity was lower than in 2003 (an average intensity of $34^{\circ} \mathrm{C}$ in 2003 versus an average intensity of $18.6^{\circ} \mathrm{C}$ in 2009). No heat waves are identified in 1995 , and a very low number of events is estimated for 2000 and 2004. In addition, very low intensities can be observed for the estimated heat waves in 2011.

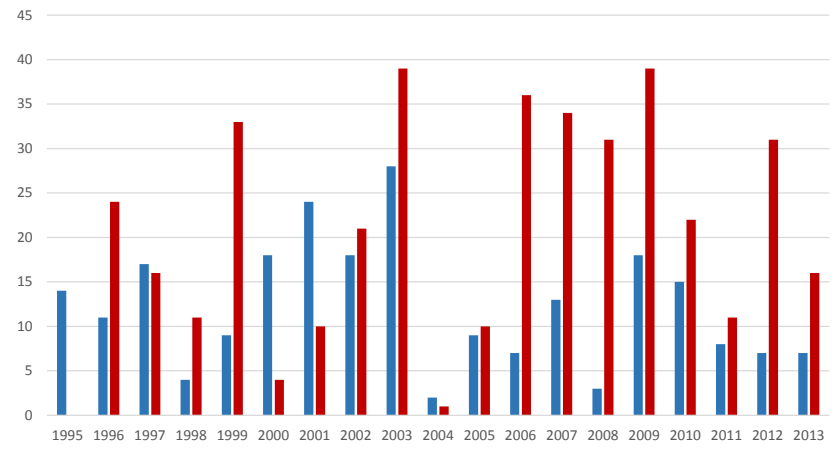

Figure 2. Number of provinces affected by heat waves (red) and significant negative yield anomalies (in blue) in the period 19952013.

The number of provinces with significant negative yield anomalies is shown in Fig. 2. A peak in 2003 is evident, as well as the very low number of negative yield anomalies in 1998, 2004 and 2008. The boxplot of annual yield anomalies across all provinces is shown in Fig. 3. A change after 2003 seems to affect the annual yields; in fact, a higher number of provinces experienced annual negative yield anomalies during the period 1995-2003 compared to the period 20042013. The factors behind this change are beyond the objectives of this study; however, the adoption of new wheat varieties over time might have played an important role.

The spatial analysis of the intensity of the early heat waves is shown in Fig. 4. The average intensity of the early heat waves is highest over the provinces in central Italy, Basilicata and Apulia (southern and south-eastern Italy), while in Sicily and Calabria (southern Italy) all provinces show low intensity values.

As an example, the spatial pattern of the early 2003 heat waves is shown in Fig. 5. The average intensity of the early 


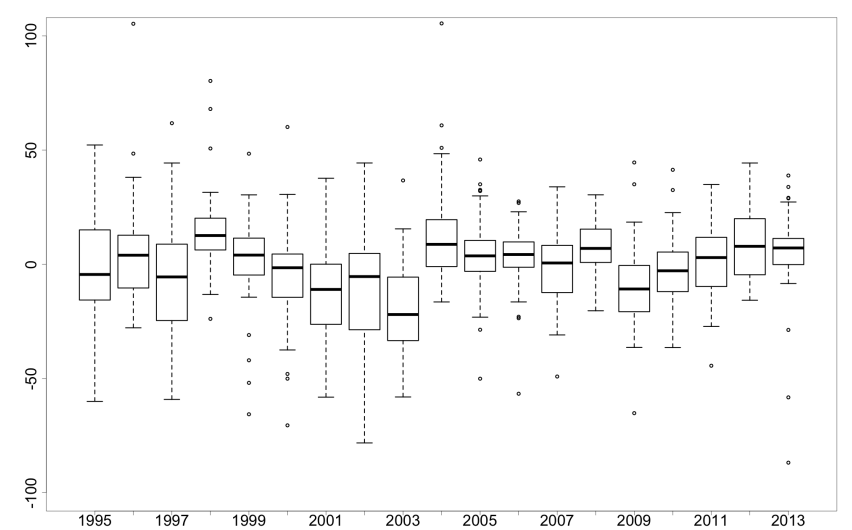

Figure 3. Annual boxplots of yield anomalies in the selected 39 Italian provinces.

heat waves reaches the highest values in Apulia (southeastern Italy), Basilicata (southern Italy), Lazio and Tuscany (central-western Italy), and Umbria (central Italy). In these regions heat waves occurred during the first half of June, with maximum daily temperatures above $35^{\circ} \mathrm{C}$. The effects on durum wheat yields are evident in most provinces of Apulia (south-eastern Italy), where reductions up to $-52.5 \%$ (province of Bari) were recorded. Negative anomalies of annual yield exceeding -45 and $-30 \%$ were also registered in the provinces of Viterbo/Grosseto (central-western Italy) and Basilicata (southern Italy), respectively.

In 2009, a negative peak of yield anomalies, $-65 \%$, was recorded in Taranto (south-eastern Italy), associated with early heat waves with an intensity equal to $24^{\circ} \mathrm{C}$. In the same year, another significant negative yield anomaly (exceeding $-30 \%$ ) associated with early heat waves was registered in Bologna (northern Italy). The early heat waves of 2007 mainly affected the province of Apulia (south-eastern Italy), which recorded a negative yield anomaly exceeding $-30 \%$.

A homogeneous spatial pattern is observed in the total number of years with significant negative yield anomalies that in most of the provinces is equal to 6 (not shown). Concerning the concurrence of early heat waves and significant negative yield anomalies, some remarkable spatial differences can be observed in Fig. 6. There are provinces where a clear signal can be identified, others where the percentage of concurrent heat waves/significant negative yield anomalies with respect to the total number of years with significant negative yield anomalies is lower than $35 \%$. The highest number of concurrent events is reached over Ferrara (northern Italy); Pesaro-Urbino, Teramo and Chieti (central-eastern Italy); Rome and Viterbo (central-western Italy); Benevento (southwestern Italy); Foggia and Taranto (south-eastern Italy); and Cosenza (southern Italy). In the most important production area, located in south-eastern Italy, the percentage of concurrent events exceeds $80 \%$. Such high values are also observed

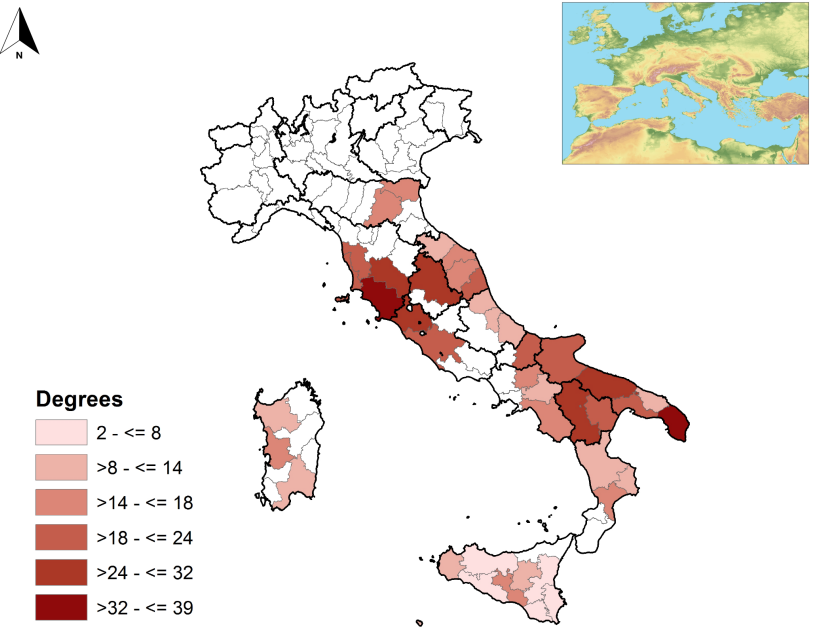

Figure 4. Average intensity of the identified early heat waves in the period 1995-2013.

in central-western Italy (Viterbo and Rome). Sicily is characterised by values lower than $55 \%$, despite the high number of years with early heat waves. This behaviour can be better understood by analysing when early heat waves affected the Sicilian provinces. Indeed, the identified heat waves are more frequent at the end of June, after the durum wheat maturity and in some years after the harvest. On the contrary, in central Italy, Apulia (south-eastern Italy) and Emilia Romagna (northern Italy) early heat waves are more frequent in May and at the beginning of June. Furthermore, the analysis of the cumulated climatic water balance from October (timing of sowing) to May in the Sicilian provinces (carried out for the years with negative yield anomalies but without early heat waves, i.e. 27 cases) highlights that $80 \%$ of years with significant negative yield anomalies have a negative accumulated water balance (not shown). In particular, the extreme negative values of 2002 yields in all Sicilian provinces are concurrent with extremely negative values of cumulated water balance. Similarly for 2001, negative yield anomalies and negative values of climatic water balance are observed in most of the Sicilian provinces. During 2001 and 2002, significant dry conditions occurred from the winter season until June, with cumulated rainfall constantly well below the longterm average ( $-515 \mathrm{~mm}$ in 2002 and $-480 \mathrm{~mm}$ in 2001).

\section{Conclusions and discussion}

Heat stress impact on wheat has been widely investigated by using different approaches: plots covered with tunnels (Ferris et al., 1998), temporary transferring pots to glasshouse during grain filling (Corbellini et al., 1997) or late sowing and supplemental infrared heating in the field (Ottman et al., 2012). Only recently, yield reduction related to heat stress has been quantified by using crop models (Asseng et al., 

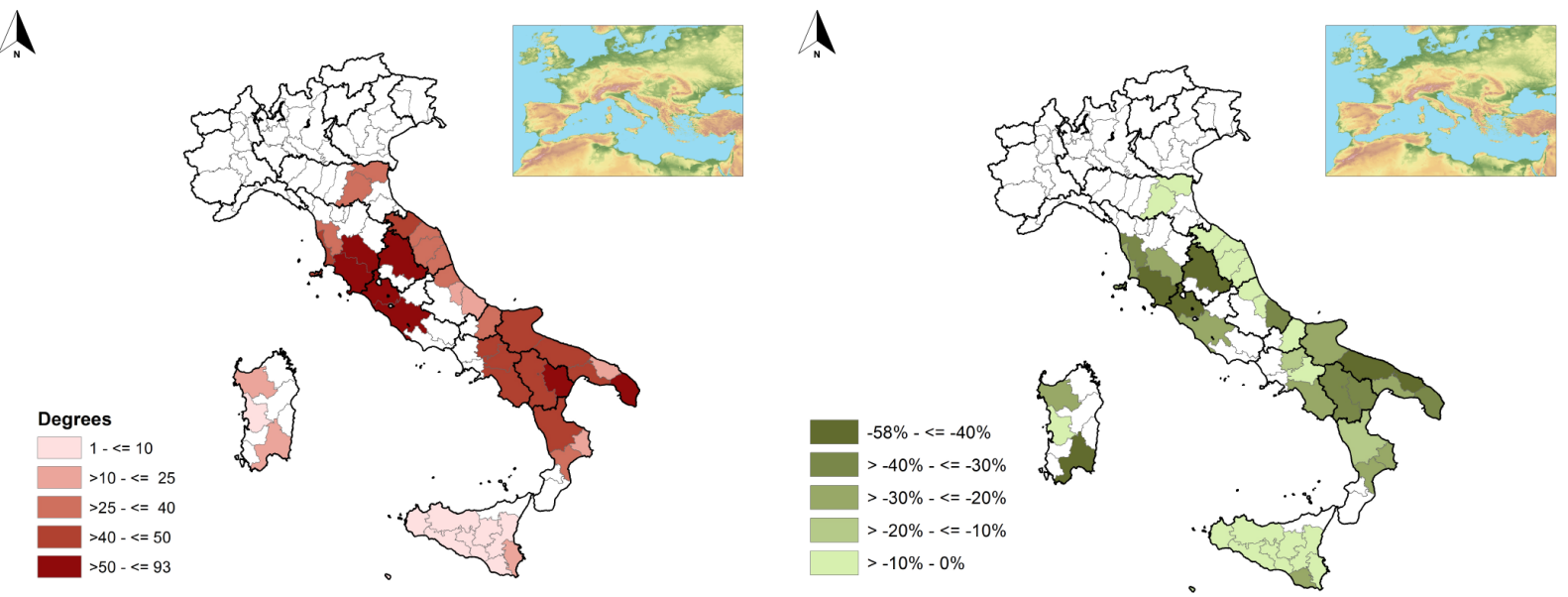

Figure 5. Left panel: intensity of the early heat waves that occurred in 2003, values in degrees. Right panel: yield anomalies in 2003.

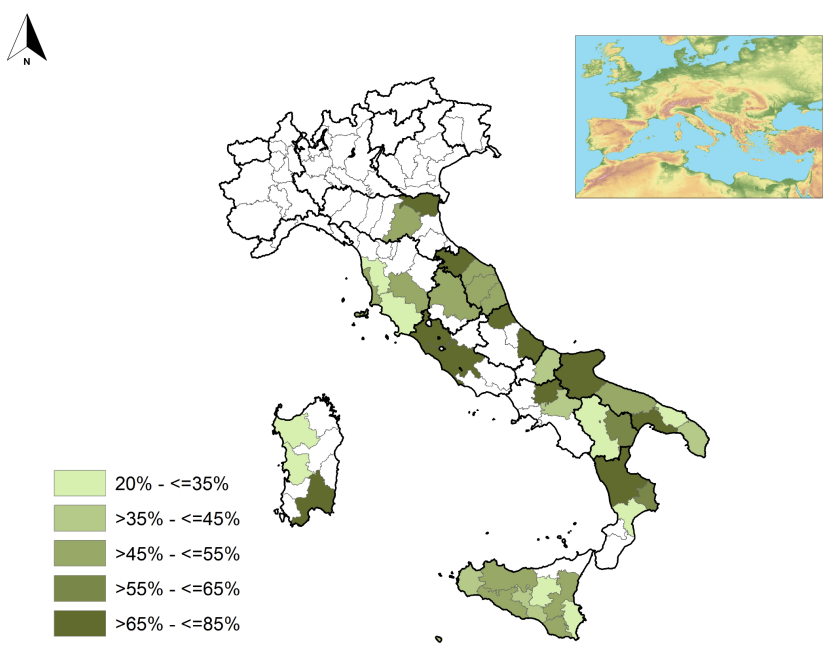

Figure 6. Number of concurrent early heat waves and significant negative yield anomalies in the period 1995-2013 (expressed in percentage with respect to the total number of year with significant negative yield anomalies).

2011; Teixeira et al., 2013) and ensemble of crop models (Webber et al., 2015). These studies substantially agree on the strong effect of extreme temperatures in the reduction of final yields. However, the magnitude of reduction, the mechanism of the effects of extreme temperature on crops and the identification of temperature thresholds at different crop growing stages are still under debate (Luo, 2011).

In general, durum wheat is more tolerant to heat stress when compared with soft wheat, as stomatal conductance and transpiration are less affected by high temperature (Dias et al., 2011). Nevertheless, durum wheat frequently experiences heat stress in the regions where it is mainly grown (southern Europe, western Asia, and northern Africa). In addition, there is limited literature on the effects of heat stress on durum wheat yield compared with soft wheat ( $\mathrm{Li}$ et al., 2013).

A substantial new approach has been here applied: a spatial characterisation of early heat waves in the crop relevant period (May-June), an investigation of concurrency of heat waves and significant negative yield anomalies of durum wheat at the province level of Italy. This analysis has confirmed, as expected, the 2003 event and has identified other significant events, for instance in 2006, 2007 and 2009. The development and growth of annual crops were greatly influenced by heat stress during 2003, as shown by the very low values of durum wheat yields in Apulia (southern Italy), Viterbo and Grosseto (central-western Italy) and in Basilicata (southern Italy). A very low number of provinces with negative yield anomalies and highest values in the average yields was found in 1998, 2004 and 2008. In particular, no event has been identified in 2004 when the second highest average yield value was registered. The spatial analysis highlights the high values of concurrent heat waves/annual negative yield anomalies for the following provinces: Ferrara (northern Italy); Pesaro-Urbino, Teramo and Chieti (central-eastern Italy); Rome and Viterbo (central-western Italy); Benevento (south-western Italy); Foggia, Taranto (south-eastern Italy); and Cosenza (southern Italy). In Sicily, the concurrent heat waves/significant negative yield anomalies are lower than $55 \%$, mainly due to timing of early heat waves, more frequent at the end of June. In this period, early heat waves could not affect the final yields in Sicily since they occurred after the durum wheat maturity and in some years after the harvest. Furthermore, the analysis of the cumulated climatic water balance in the Sicilian provinces has shown that the significant negative yield anomalies, recorded in 2002 and 2001, are associated with prolonged water stress.

This study has also highlighted a change after 2003 in the annual yield time series of durum wheat. The significant 2003 event seems to have marked a turning point, probably in the choice of the variety that, together with other unknown 
factors, could have changed the average and the variability of the durum wheat yield in Italy. In the last decade new wheat varieties (i.e. cv. Simeto, Duilio and Svevo), characterised by high productivity index (Arduini et al., 2006), have been regularly introduced in Italy, decreasing the weight of older varieties such as cv. Creso. However, it is important to notice that those new varieties have shown an earlier anthesis but a maturity phase similar to older ones. Anyway, additional data must be retrieved to confirm and better understand the aforementioned change.

Finally, this study has pointed to the important effects of early heat waves especially in the main Italian areas of durum wheat production as well as remarkable spatial differences. It is worth highlighting that other factors can act in modulating and changing the effect of heat waves, such as the combination of heat wave and drought as productivity of wheat is reduced considerably when combined stress is applied (Barnabás et al., 2008). A specific evaluation of the effects of early heat waves on pre- and/or post-anthesis phases should be tested as a next step (retrieving metadata on phenological phases), considering that recent studies (Luo, 2011) have highlighted the effects of high temperature imposed at pre-anthesis phase being greater than the ones imposed at post-anthesis.

Finally, longer time series are needed to gain a better understanding of such a complex interaction.

Acknowledgements. The authors thank Fabrizio Quaranta for providing information related to the certified seed for the most important varieties of durum wheat sown in Italy over time. We thank two anonymous referees for their comments and suggestions that helped to improve the quality of this study.

Edited by: D. Gomis

Reviewed by: two anonymous referees

\section{References}

Allen, R.G., Pereira, L. S., Raes, D., and Smith, M.: Crop Evapotranspirati on: Guidelines for computing crop water requirements, FAO Irrigation and Drainage Paper No. 56, FAO, Rome, 1998.

Arduini, I., Masoni, A., Ercoli, L., and Mariotti, M.: Grain yield, and dry matter and nitrogen accumulation and remobilization in durum wheat as affected by variety and seeding rate, Eur. J. Agron., 25, 309-318, 2006.

Asseng, S., Foster, I., and Turner, N. C.: The impact of temperature variability on wheat yields, Global Change Biol., 17, 997-1012, 2011.

Barnabás, B., Jäger, K., and Fehér, A.: The effect of drought and heat stress on reproductive processes in cereals, Plant Cell Environ., 31, 11-38, 2008.

Black, E., Blackburn, M., Harrison, G., Hoskins, B., and Methven, J.: Factors contributing to the summer 2003 European heatwave, Weather, 59, 217-223, 2004.
Boote, K. J., Allen, L. H., Prasad, P. V. V., Baker, J. T., Gesch, R. W., Synder, A. M., Pan, D., and Thomas, J. M. G.: Elevated temperature and $\mathrm{CO}_{2}$ impacts on pollination, reproductive growth and yield of several globally important crops, J. Agr. Meteorol., 60, 469-474, 2005.

Corbellini, M., Canevar, M. G., Mazza, L., Ciaffi, M., Lafiandra, D., and Borghi, B.: Effect of the duration and intensity of heat shock during grain filling on dry matter and protein accumulation, technological quality and protein composition in bread and durum wheat, Funct. Plant Biol., 24, 245-260, 1997.

Dalla Marta, A., Grifoni, D., Mancini, M., Zipoli, G., and Orlandini, S.: The influence of climate on durum wheat quality in Tuscany, Int. J. Biometeorol., 55, 87-96, 2011.

Della-Marta, P. M., Haylock, M. R., Luterbacher, J., and Wanner, H.: Doubled length of western European summer heat waves since 1880, J. Geophys, Res., 112, D15103, doi:10.1029/2007JD008510, 2007.

Dias, A. S. and Lidon, F. C.: Evaluation of Grain Filling Rate and Duration in Bread and Durum Wheat, under Heat Stress after Anthesis, J. Agron. Crop Sci., 195, 137-147, 2009.

Dias, A. S., Semedo, J., Ramalho, J. C., and Lidon, F. C.: Bread and durum wheat under heat stress: a comparative study on the photosynthetic performance, J. Agron. Crop Sci., 197, 50-56, 2011.

Eyshi Rezaei, E., Webber, H., Gaiser, T., Naab, J., and Ewert, F.: Heat stress in cereals: mechanisms and modelling, Eur. J. Agron., 24, 98-113, 2015.

Ferris, R., Ellis, R. H., Wheeler, T. R., and Hadley, P.: Effect of high temperature stress at anthesis on grain yield and biomass of field-grown crops of wheat, Ann. Bot., 82, 631-639, 1998.

Gobin, A.: Impact of heat and drought stress on arable crop production in Belgium, Nat. Hazards Earth Syst. Sci., 12, 1911-1922, doi:10.5194/nhess-12-1911-2012, 2012.

Hartmann, D. L., Klein Tank, A. M. G., Rusticucci, M., Alexander, L. V., Brönnimann, S., Charabi, Y., Dentener, F. J., Dlugokencky, E. J., Easterling, D. R., Kaplan, A., Soden, B. J., Thorne, P. W., Wild, M., and Zhai, P. M.: Observations: Atmosphere and Surface, in: Climate Change 2013: The Physical Science Basis. Contribution of Working Group I to the Fifth Assessment Report of the IPCC, edited by: Stocker, T. F., Qin, D., Plattner, G. K., Tignor, M., Allen, S. K., Boschung, J., Nauels, A., Xia, Y., Bex, V., and Midgley, P. M., Cambridge University Press, UK and New York, 2013.

Johnson, R. C. and Kanemasu, E. T.: Yield and development of winter wheat at elevated temperatures, J. Agron., 75, 561-565, 1983.

Kendall, M. G.: Rank Correlation Methods, Griffin, London, 1975.

Kuglitsch, F. G., Toreti, A., Xoplaki, E., Della-Marta, P. M., Zerefos, C. S., Türkes, M., and Luterbacher, J.: Heat wave changes in the eastern Mediterranean since 1960, Geophys. Res. Lett., 37, L04802, doi:10.1029/2009GL041841, 2010.

Li, Y.-F., Wu, Y., Hernandez-Espinosa, N., and Pena, R. J.: Heat and drought stress on durum wheat: responses of genotypes, yield, and quality parameters, J. Cereal Sci., 57, 398-404, 2013.

Luo, Q.: Temperature thresholds and crop production: a review, Climatic Change, 109, 583-598, 2011.

Mann, H. B.: Nonparametric tests against trend, Econometrica, 13, 245-259, 1945.

Nakamoto, H., and Hiyama, T.: Heat shock proteins and temperature stress, in: Handbook of Plant and Crop Stress, edited by: Pessarakli, M., Marcel Dekker, New York, 399-416, 1999. 
Ottman, M., Kimball, B., White, J., and Wall, G.: Wheat growth response to increased temperature from varied planting dates and supplemental infrared heating, Agron. J., 104, 7-16, 2012.

Porter, J. R., and Gawith, M.: Temperatures and the growth and development of wheat: a review, Eur. J. Agron., 10, 23-36, 1999.

Rosenzweig, C. and Hillel, D.: Climate Change and the Global Harvest: Potential Impacts of the Greenhouse Effect on Agriculture, Oxford University Press, 1998.

Schär, C., Vidale, P. L., Lüthl, D., Frei, C., Häberli, C., Liniger, M. A., and Appenzeller, C.: The role of increasing temperature variability in European summer heatwaves, Nature, 427, 332336, 2004.

Schlenker, W. and Roberts, M. J.: Nonlinear temperature effects indicate severe damages to U. S. crop yields under climate change, P. Natl. Acad. Sci. USA, 106, 15594-15598, 2009.

Semenov, M. A. and Shewry, P. R.: Modelling Predicts That Heat Stress, Not Drought, Will Increase Vulnerability of Wheat in Europe, Scient. Reports, 1, 1-5, doi:10.1038/srep00066, 2011.

Sen, P. K.: Estimates of the regression coefficient based on Kendall's tau, J. Am. Stat. Assoc., 63, 1379-1389, 1968.

Siebert, S., Ewert, F., Rezaei, E. E., Kage, H., and Graß, R.: Impact of heat stress on crop yield - on the importance of considering canopy temperature, Environ. Res. Lett., 9, 044012, doi:10.1088/1748-9326/9/4/044012, 2014.

Slafer, G. A. and Rawson, H. M.: Rates and cardinal temperatures for processes of development in wheat: Effects of temperature and thermal amplitude, Aust. J. Plant Physiol., 22, 913-926, 1995.

Stone, P. J. and Nicolas, M. E.: Effect of timing of heat stress during grain filling on two wheat varieties differing in heat tolerance, I. Grain Growth, Aust. J. Plant. Physiol., 22, 927-934, 1995.

Teixeira, E. I., Fischer, G., van Velthuizen, H., Walter, C., and Ewert, F.: Global hot-spots of heat stress on agricultural crops due to climate change, Agr. Forest Meteorol., 170, 206-215, 2013.
Toreti, A. and Desiato, F.: Changes in temperature extremes over Italy in the last 44 years, Int. J. Climatol., 28, 733-745, 2008.

Van der Goot, E., Supit, I., Micale, F., Orlandi, S., Boogaard, H., van Diepen, K., Otten, H., Geuze, M., and Schulze, D.: Meteorological data collection processing and analysis, in: Methodology of the MARS crop yield forecasting system, Vol. I, EUR 21291 EN/1, edited by: Micale, F. and Genovese, G., European Commission, Luxembourg, 2004.

Viswanathan, C. and Khanna-Chopra, R.: Effect of heat stress on grain growth, starch synthesis and protein synthesis in grains of wheat (Triticum aestivum L.) varieties differing in grain weight stability, J. Agron. Crop Sci., 186, 1-7, 2001.

Wassmann, R., Jagadish, S. V. K., Sumfleth, K., Pathak, H., Howell, G., Ismail, A., Serraj, R., Redona, E., Singh, R. K., and Heuer, S.: Regional vulnerability of climate change impacts on Asian rice production and scope for adaptation, Adv. Agron., 102, 91-103, 2009.

Webber, H., Martre, P., Asseng, S., Kimball, B., White, J., Ottman, M., Wall, G., De Sanctis, G., Doltra, J., Grant, R., Kassie, B., Maiorano, A., Olesen, J. E., Ripoche, D., Eyshi Rezaei, E., Semenov, M. A., Stratonovitch, P., and Ewert, F.: Canopy temperature for simulation of heat stress in irrigated wheat in a semi-arid environment: a multi-model comparison, Field Crop Res., in review, 2015

Wheeler, T. R., Hong, T. D., Ellis, R. H., Batts, G. R., Morison, J. I. L., and Hadley, P.: The duration and rate of grain growth, and harvest index, of wheat (Triticum aestivum $L$.) in response to temperature and $\mathrm{CO}_{2}$, J. Exp Bot., 47, 623-630, 1996a.

Wheeler, T. R., Batts, G. R., Ellis, R. H., Hadley, P., and Morison, J. I. L.: Growth and yield of winter wheat (Triticum aestivum) crops in response to $\mathrm{CO}_{2}$ and temperature, J. Agr. Sci., 127, $37-$ 48, 1996b.

Wollenweber, B., Porter, J. R., and Schellberg, J.: Lack of interaction between extreme high temperature events at vegetative and reproductive growth stages in wheat, J. Agron. Crop Sci., 189, 142-150, 2003. 